\title{
Inherited arrhythmia syndrome predisposing to sudden cardiac death
}

\author{
Yun Gi Kim, Suk-Kyu Oh, Ha Young Choi, and Jong-Il Choi
}

Division of Cardiology, Department of Internal Medicine, Korea University College of Medicine, Seoul, Korea

Received: September 3, 2020 Accepted: October 27, 2020

\author{
Correspondence to \\ Jong-Il Choi, M.D. \\ Division of Cardiology, \\ Department of Internal \\ Medicine, Korea University \\ College of Medicine, 73 \\ Goryeodae-ro, Seongbuk-gu, \\ Seoul 02841, Korea \\ Tel: +82-2-920-5445 \\ Fax: $+82-2-927-1478$ \\ E-mail:jongilchoi@korea.ac.kr \\ https://orcid.org/0000-0001- \\ 6617-508X
}

Inherited arrhythmia (IA) is one of the main causes of sudden cardiac death (SCD) in young people, and is reported to be a more prevalent cause of SCD in Asia than in Western countries. IAs are a group of genetic disorders caused by mutations in genes encoding cardiac ion channels, leading to electrophysiological characteristics that often occur in the absence of structural abnormalities. Channelopathies, such as long QT syndrome and Brugada syndrome, carry a potential risk of life-threatening ventricular tachyarrhythmias that predispose to SCD, although early prediction and prevention of the risk remain challenging. Recent advances in genetic testing have facilitated risk stratification as well as a precise diagnosis for IA, despite ongoing debates about the implications. Herein, we provide epidemiological data, a pathophysiological overview, and the current clinical approach to IAs related to SCD. In addition, we review the general issues arising from genetic testing for IAs.

Keywords: Death, sudden, cardiac; Inherited arrhythmia; Channelopathies; Genetic testing; Precision medicine

\section{INTRODUCTION}

Sudden cardiac death (SCD) is a major global health burden $[1,2]$. A substantial proportion of SCD is related to coronary artery disease and heart failure $[1,3]$. However, SCD can occur in healthy patients without overt heart disease.4 These non-structural causes of SCD often occur in relatively young patients without prior heart disease and are referred to as inherited arrhythmia (IA) syndrome $[3,4]$. When appropriate resuscitation is not performed during the acute event, IA can cause grave damage both to the patient and to his or her family. The underlying pathophysiology of IA has not been fully established; however, recent advances in technology for molecular biology and high throughput testing have uncovered the genetic basis for IA syndrome, which has enabled identification and targeting of the culprit substrate $[3,5]$.
IA consists mainly of cardiac channelopathies such as Brugada syndrome (BrS), long QT syndrome (LQTS), short QT syndrome (SQTS), and catecholaminergic polymorphic ventricular tachycardia (CPVT) [3,6-8]. Early repolarization syndrome (ERS) and idiopathic ventricular fibrillation (IVF) are other primary electrical disorders. Nonischemic cardiomyopathies, such as hypertrophic cardiomyopathy, dilated cardiomyopathy, or arrhythmogenic right ventricular cardiomyopathy (ARVC), are also genetic disorders that have a risk of SCD.

The IAs have certain clinical characteristics. First, the initial manifestation may be lethal or a severe form like cardiac arrest or syncope due to ventricular tachyarrhythmias. Second, diagnosis of the disease and prediction for SCD may be difficult because of a lack of clinical clues, and structural abnormalities in imaging studies are rare. Third, IA is a genetic or familial disease, and is not curable. Fourth, primary prevention for SCD in 
clinical practice using an implantable cardioverter-defibrillator (ICD) is still controversial.

In this review, we provide epidemiological, clinical and genetic overviews of IAs that predispose to SCD. In addition, we provide a current update to the clinical approach and genetic testing for IA.

\section{EPIDEMIOLOGY OF SCD AND INHERITED ARRHYTHMIAS}

The estimated incidence of SCD in North America and Europe is $50-100$ cases per 100,000 person-years of follow-up $[6,9,10]$. The incidence is higher in people older than 35 years with one case per 1,000 person-years of follow-up; however, the risk of SCD is not negligible in people younger than 35 years [11]. SCD can occur not only by ventricular fibrillation (VF) or ventricular tachycardia (VT) but also with pulseless electrical activity or asystole. Furthermore, VF and VT can degenerate into pulseless electrical activity or asystole if left untreated. Estimation of the incidence of IA is made more complicated because substantial proportions of VF and VT are due to structural heart disease such as coronary artery atherosclerosis [12]. According to data from Western countries, coronary artery disease is responsible for $60 \%$ to $80 \%$ of SCD, while the proportion of SCD with underlying IA is $<5 \%[13,14]$. However, Japanese data indicated that primary electrical disorders related to channelopathies were estimated to be responsible for $10 \%$ of SCDs [15]. The proportion of IA in people who experienced SCD in South Korea may be higher than in Western countries and similar to or higher than in Japan. Based on the Korean National Health Insurance Service database, among 1,125,691 people included in the sample cohort, the overall incidence of sudden cardiac arrest was 48.7 per 100,000 person-years, and the rate of sudden unexplained death was $14.7 \%$ in patients with SCD [16]. Roh et al. [17] also demonstrated that among patients who received an ICD, identified using the Health Insurance Review and Assessment Service database, the proportion of IA as an etiology associated with the ICD was $21.1 \%$. According to data from the Korean Inherited Arrhythmia Registry, among 265 probands clinically diagnosed with IAs, IVF was the most common ( $\mathrm{n}=99,37.3 \%)$, followed by BrS ( $\mathrm{n}=90,34.0 \%)$ and LQTS $(\mathrm{n}=54,20.4 \%)$, and among 128 family members, about half were related to a patient with $\mathrm{BrS}(\mathrm{n}=62,48.4 \%)$, followed by LQTS ( $\mathrm{n}$ $=39,30.5 \%)$ and $\operatorname{IVF}(n=19,14.8 \%)$ (Fig. 1) [18]. The three most common IAs (BrS, IVF, and LQTS) accounted for $>90 \%$ of IAs in the probands and their family members in the Korean population.
Patients $(n=265)$

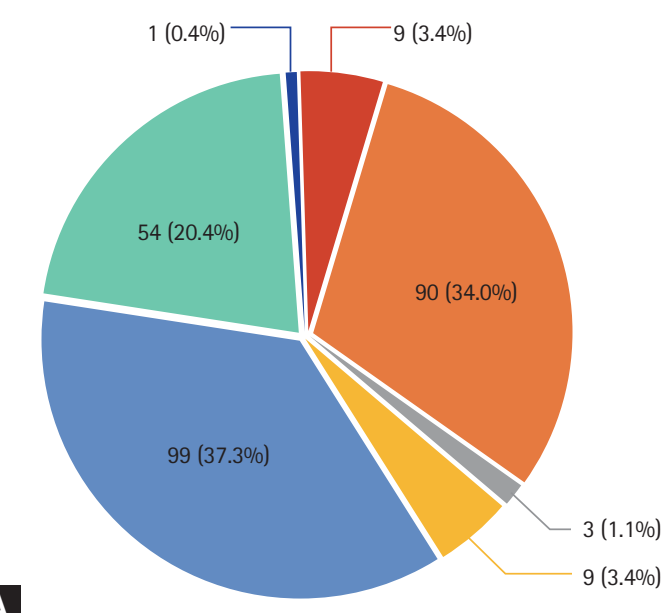

Family members $(n=128)$

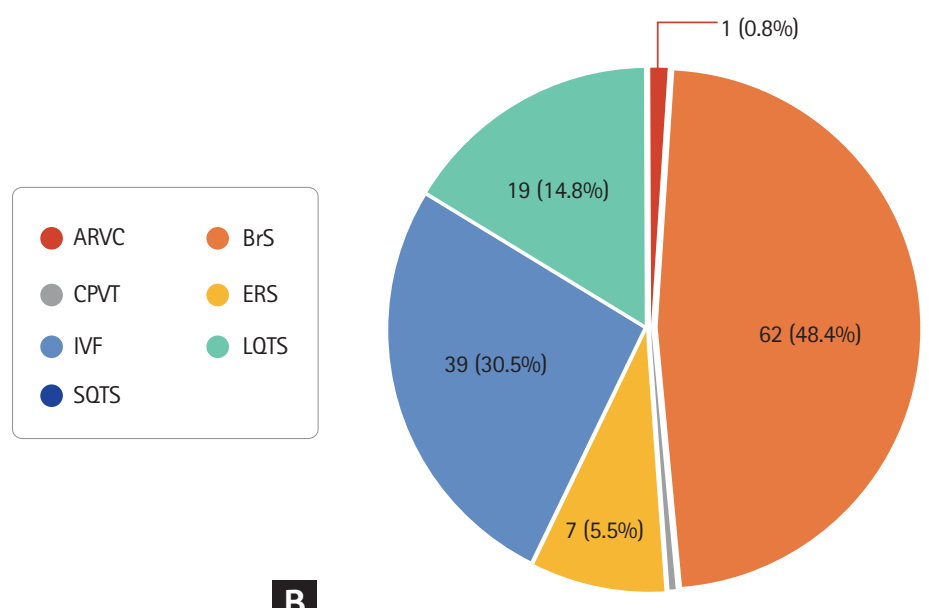

Figure 1. Distribution of inherited arrhythmias in probands (A) and their family members (B) in the Korean population [18]. ARVC, arrhythmogenic right ventricular cardiomyopathy; BrS, Brugada syndrome; CPVT, catecholaminergic polymorphic ventricular tachycardia; ERS, early repolarization syndrome; IVF, idiopathic ventricular fibrillation; LQTS, long QT syndrome; SQTS, short QT syndrome. 


\section{CLINICAL APPROACH TO INHERITED ARRHYTHMIA SYNDROME}

Excitation contraction coupling in the cardiomyocyte is a core process generating heart rhythm, which is mediated by harmonized ionic currents through various ion channels that are imbedded in the sarcolemma. Alterations in the function of cardiac ion channels by genetic mutations can cause electrical heterogeneity and subsequent initiation of ventricular tachyarrhythmias, which are called channelopathies. Gain- or loss-of-function of cardiac ion channels reveal no structural abnormalities of the heart in imaging studies. Major forms of channelopathies responsible for SCD include BrS, LQTS, SQTS, CPVT, ERS, and IVF [19-22]. The overall diagnostic approach is summarized in Fig. 2. The underlying genetic pathophysiology and a current clinical update of the channelopathies are reviewed in the following section.

\section{LONG QT SYNDROME}

Patients with LQTS experience lethal ventricular arrhythmias accompanied by prolongation of the QT interval reflecting an excessive prolongation in the duration of cardiac repolarization (Fig. 3). An epinephrine challenge test can unmask prolongation of the QT interval in patients with 'concealed LQTS' who show a normal range of QT intervals on their resting electrocardiography (ECG). Patients with LQTS are diagnosed by an LQTS risk score > 3, a corrected QT (QTc) interval for heart rate using Bazett's formula $\geq 480 \mathrm{~ms}$ in repeated ECGs in the absence of a secondary cause for QT prolongation, or an unequivocally pathogenic mutation in one of the LQTS genes [23]. Among 20 genes that have been discovered, potassium voltage-gated channel subfamily Q member 1 (KCNQ1; LQT1), potassium voltage-gated channel subfamily $\mathrm{H}$ member $2(\mathrm{KCNH} 2$;

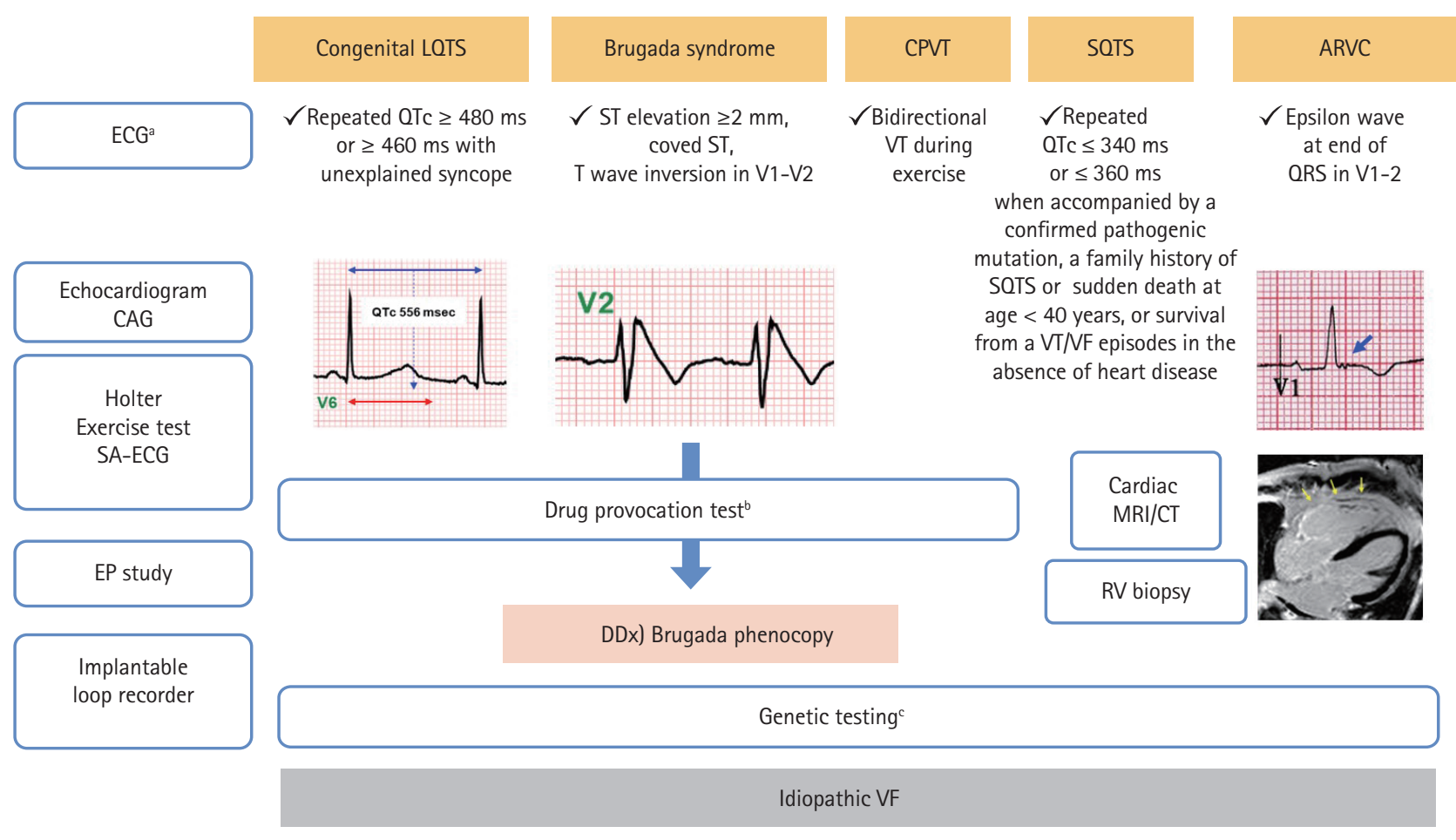

Figure 2. A diagnostic algorithm in inherited arrhythmia syndrome. LQTS, long QT syndrome; CPVT, catecholaminergic polymorphic ventricular tachycardia; SQTS, short QT syndrome; ARVC, arrhythmogenic right ventricular cardiomyopathy; ECG, electrocardiogram; CAG, coronary angiography; SA, signal averaged; EP, electrophysiological; QTc, corrected QT; VT, ventricular tachycardia; DDx, differential diagnosis; MRI, magnetic resonance image; CT, computed tomography; RV, right ventricle; VF, ventricular fibrillation. ${ }^{a}$ Bazett or Fridericia formula: standard and upper level (up to the 2 nd or 3 rd intercostal space), ${ }^{b}$ Epinephrine for LQTS, CPVT: procainamide or flecainide for Brugada syndrome, ${ }^{\mathrm{C}}$ Next-generation sequencing panels for channelopathies and cardiomyopathies. 

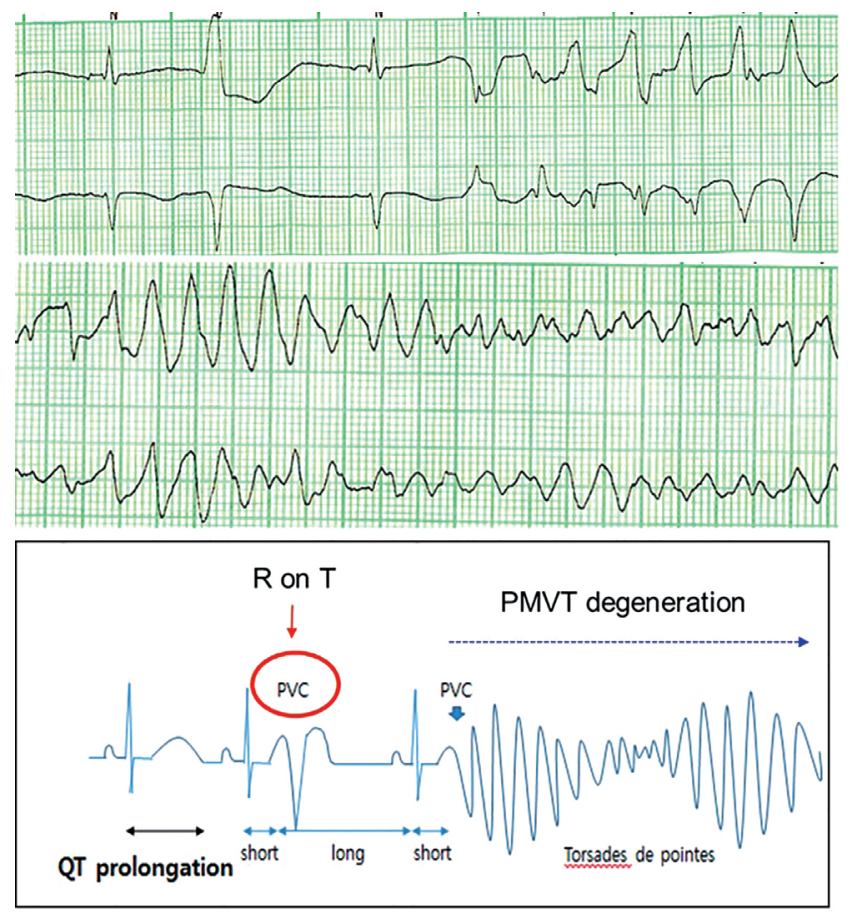

Figure 3. A 24-year-old female patient's electrocardiographies showed marked prolongation of the QT interval and subsequent polymorphic ventricular tachycardia (PMVT) (top). Her genetic testing result was a positive genotype of potassium voltage-gated channel subfamily $\mathrm{H}$ member $2\left(\mathrm{KCNH}_{2}\right)$. She was diagnosed with long QT syndrome (LQTS) type 2. The mechanism of lethal ventricular tachyarrhythmia in LQTS (bottom). PVC, premature ventricular contraction.
LQT2), and sodium voltage-gated channel alpha subunit ${ }_{5}\left(\mathrm{SCN}_{5} \mathrm{~A} ; \mathrm{LQT}_{3}\right)$ are the most common LQTS genes, accounting for about $90 \%[3,20,24,25]$. Triggers for cardiac events and ECG morphologies that may be characteristic according to the genotypes can assist in management [26]. Affected patients show high mortality rates $>20 \%$ within 1 year after the first syncopal episode if left untreated $[26,27]$. Schwartz reported a significantly reduced mortality in LQTS patients who received beta-blocker or surgical antiadrenergic therapy [27]. Patients with genetic LQTS treated with a beta-blocker experience a high rate of cardiac events, particularly those with LQT2 and LQT3 genotypes [28]. Recent studies have demonstrated the superiority of nadolol, a beta-blocker, in reducing the risk of life-threatening arrhythmic events, suggesting preferential management with nadolol [29,30]. An ICD with the use of a beta-blocker is recommended in LQTS patients with previous cardiac arrest. Left cardiac sympathetic denervation should be considered when a beta-blocker is either not effective, not tolerated or contraindicated, or when an ICD is contraindicated or refused [22]. Table 1 shows the clinical characteristics of LQTS in Korean and international registries [18,31-35].

\section{BRUGADA SYNDROME}

$\mathrm{BrS}$ is an inherited disorder associated with lethal ventricular arrhythmias and results in an increased risk

Table 1. Clinical characteristics of patients with LQTS in international registries

\begin{tabular}{|c|c|c|c|c|c|c|}
\hline Characteristic & $\begin{array}{l}\text { Korean IA } \\
\text { registry [18] } \\
(\mathrm{n}=54)\end{array}$ & $\begin{array}{l}\text { Korean } \\
\text { single } \\
\text { center [31] } \\
(\mathrm{n}=62)\end{array}$ & $\begin{array}{l}\text { Burns et al. [32] } \\
\text { (Austrailia) } \\
(\mathrm{n}=78)\end{array}$ & $\begin{array}{l}\text { Earle et al. [33] } \\
\text { (New Zealand) } \\
\quad(n=309)\end{array}$ & $\begin{array}{c}\text { Goldenberg } \\
\text { et al. }[34] \\
\text { (7 multi-national) } \\
(\mathrm{n}=1,861)\end{array}$ & $\begin{array}{l}\text { Sauer et al. [35] } \\
\text { (international } \\
\text { LQTS registry) } \\
\quad(\mathrm{n}=812)\end{array}$ \\
\hline Mean age, yr & $38 \pm 17$ & 15.8 & $40 \pm 18$ & 30 & NA & 32 \\
\hline Female sex & $42(78)$ & $34(55)$ & $57(73)$ & $184(60)$ & $1,075(58)$ & $469(58)$ \\
\hline History of syncope & $18(33)$ & $26(42)$ & $39(50)$ & $72(23)$ & $655(35)$ & NA \\
\hline History of SCD & $27(50)$ & $15(24)$ & $25(32)$ & $48(16)$ & $191(10)$ & NA \\
\hline Family history of SCD & $8(15)$ & NA & NA & $40(13)$ & NA & NA \\
\hline ICD implantation & $33(61)$ & $6(10)$ & $40(51)$ & NA & $223(12)$ & $9(1)$ \\
\hline QTc interval, msec & 504 & 539 & 515 & 480 & 480 & 489 \\
\hline Beta-blocker & $41(76)$ & $41(66)$ & $66(85)$ & NA & $930(50)$ & $149(18)$ \\
\hline
\end{tabular}

Values are presented as mean \pm SD or number (\%).

LQTS, long QT syndrome; IA, inherited arrhythmia; NA, not available; SCD, sudden cardiac death; ICD, implantable cardioverter defibrillator; QTc, corrected QT. 
of SCD [36]. BrS is diagnosed in patients with ST-segment elevation with type 1 morphology $\geq 2 \mathrm{~mm}$ in one or more leads among the right precordial leads V1 and/ or V2, positioned in the second, third, or fourth intercostal space, occurring either spontaneously or after a provocative drug test with intravenous or oral administration of sodium channel blockers, such as flecainide or procainamide [22]. Brugada phenocopies, which are Brugada-like ECG patterns induced by reversible conditions such as pectus excavatum, should be differentiated from true BrS [37]. Lethal arrhythmias occur predominantly in younger males (20 to 40 years old) during rest or sleep [38]. Among 19 genes known to be associated with $\mathrm{BrS}$, loss-of-function in $\mathrm{SCN}_{5} \mathrm{~A}, \mathrm{CACN}_{1} A C$, and sodium voltage-gated channel alpha subunit 10 (SCN1OA) were found individually in $>5 \%$ of positively genotyped patients [39]. However, the clinical use of genetic testing results remains limited, which may be due to oligogenic genetic susceptibility and low disease penetrance in $\mathrm{BrS}$ compared to forms of Mendelian inheritance [40]. In addition, a subset of patients with $\mathrm{BrS}$ also have other types of arrhythmias such as atrial fibrillation or conduction defects such as atrioventricular block $[3,41,42]$. Lifestyle modification is recommended in all patients with a diagnosis of BrS [23]. Drugs that may induce ST-segment elevation in right precordial leads, excessive alcohol intake, and large meals should be avoided; any fever should be promptly treated with antipyretics. An ICD is recommended in survivors of an aborted cardiac arrest or patients who have documented sustained VT, and should be considered in patients with a spontaneous type I ECG pattern and history of syncope, presumably due to an episode of VT. Table 2 shows the clinical characteristics of $\mathrm{BrS}$ in Korean and international registries [18,38,43-49].

\section{EARLY REPOLARIZATION SYNDROME}

Electrocardiographic characteristics of early repolarization include J-point (the point between the end of the QRS complex and the beginning of the ST segment) elevation, notching or slurring of the terminal part of the QRS complex, and tall and symmetric T waves (Fig. 4) [50]. Previously, early repolarization was considered a benign phenomenon that did not need further evaluation [51,52]. However, the concept has changed since the demonstration that early repolarization in ECG, particularly in the inferior and lateral leads and with greater amplitude, is associated with a significantly increased risk of lethal ventricular arrhythmias and SCD [53-55]. The term ERS is used when early repolarization shown in ECG is accompanied by clinical symptoms such as syncope or SCD. The underlying mechanism for J-point elevation and the occurrence of lethal ventricular arrhythmias in ERS has still not been fully elucidated. A

Table 2. Clinical characteristics of patients with $\mathrm{BrS}$ in international registries

\begin{tabular}{|c|c|c|c|c|c|c|c|c|c|}
\hline Characteristic & $\begin{array}{c}\text { Korean IA } \\
\text { Registry } \\
{[18]} \\
(\mathrm{n}=90)\end{array}$ & $\begin{array}{c}\text { Japanese } \\
\text { multi-center } \\
\text { registry [43] } \\
(\mathrm{n}=415)\end{array}$ & $\begin{array}{l}\text { Sieira et } \\
\text { al. [44] } \\
\text { (Belgium) } \\
(\mathrm{n}=404)\end{array}$ & $\begin{array}{c}\text { Delise } \\
\text { et al. [45] } \\
\text { (Italy) } \\
(n=320)\end{array}$ & $\begin{array}{c}\text { FINGER } \\
\text { registry } \\
{[46]} \\
(\mathrm{n}=1,029)\end{array}$ & $\begin{array}{l}\text { Eckardt } \\
\text { et al. [47] } \\
\text { (Europe) } \\
(\mathrm{n}=212)\end{array}$ & $\begin{array}{l}\text { Brugada } \\
\text { et al. [48] } \\
\text { (Europe) } \\
(n=443)\end{array}$ & $\begin{array}{l}\text { Priori et } \\
\text { al. [38] } \\
\text { (Italy) } \\
(\mathrm{n}=200)\end{array}$ & $\begin{array}{c}\text { Brugada } \\
\text { et al. [49] } \\
(\mathrm{n}=334)\end{array}$ \\
\hline Mean age, yr & $41 \pm 13$ & $46 \pm 14$ & $43 \pm 16$ & 43 & 45 & $45 \pm 6$ & $42 \pm 14$ & $41 \pm 18$ & $42 \pm 16$ \\
\hline Male sex & $84(93)$ & $403(97)$ & $235(58.2)$ & $258(81)$ & $745(72)$ & & & $152(76)$ & \\
\hline History of syncope & $27(30)$ & $99(24)$ & $114(28)$ & $105(34)$ & $313(30)$ & $65(31)$ & $100(23)$ & $34(17)$ & $73(22)$ \\
\hline History of SCD & $50(56)$ & $88(21)$ & $17(4.2)$ & NA & $62(6)$ & & & $22(11)$ & $71(21)$ \\
\hline Family history of SCD & $23(26)$ & $64(15)$ & $187(47)$ & $94(29)$ & $264(26)$ & $60(28)$ & NA & $26 / 130(22)$ & $180(54)$ \\
\hline ICD implantation & $70(78)$ & $241(58)$ & $168(42)$ & $110(34)$ & $433(42)$ & $113(53)$ & NA & $52(26)$ & $129(39)$ \\
\hline Type I ECG & $50 / 56(89)$ & $299(72)$ & NA & $174(54)$ & $468(45)$ & $125(59)$ & & $90 / 176(51)$ & NA \\
\hline $\mathrm{SCN}_{5} \mathrm{~A}$ genotype & NA & $60(14)$ & $53(22)$ & NA & $185(18)$ & $57 / 183(31)$ & NA & $28 / 130(22)$ & NA \\
\hline
\end{tabular}

Values are presented as mean $\pm \mathrm{SD}$ or number (\%).

BrS, Brugada syndrome; IA, inherited arrhythmia; FINGER, France, Italy, Netherlands, GERmany; SCD, sudden cardiac death; NA, not available; ICD, implantable cardioverter defibrillator; ECG, electrocardiogram; $S_{5} N_{5}$, sodium voltage-gated channel alpha subunit 5 . 
voltage gradient that results from transmural differences between the epicardium and endocardium during phases 1 and 2 of the cardiac action potential has been suggested as a possible mechanism of J-point elevation by Antzelevitch et al. $[50,56,57]$. They also suggested that eliminating the arrhythmia substrate might reduce the future recurrence of lethal ventricular arrhythmias $[58,59]$. Several novel genetic variations in potassium inwardly rectifying channel subfamily J member 8 (KCNJS) and $\mathrm{SCN}_{5} \mathrm{~A}$ have been reported to be potential genetic abnormalities responsible for ERS [60,61].

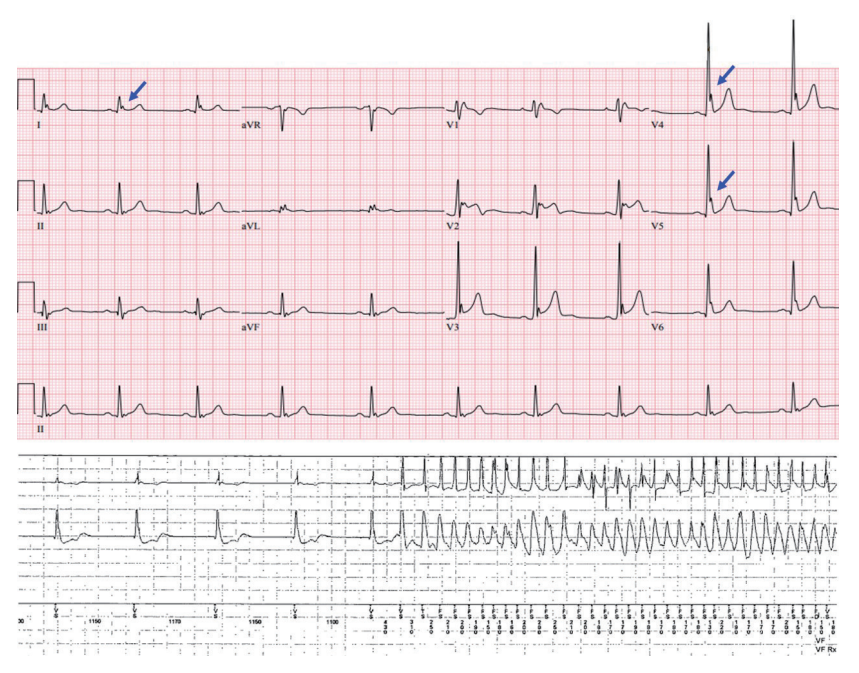

Figure 4. Electrocardiogram in a 26-year-old man showed early repolarization syndrome with prominent J waves (arrows) in inferolateral leads (top). Implantable cardioverter defibrillator examination demonstrated an episode of sudden onset ventricular fibrillation (bottom).

\section{IDIOPATHIC VENTRICULAR FIBRILLATION}

IVF is diagnosed when no other cause is identified despite a systematic evaluation including ECG, imaging studies, drug challenge test and genetic evaluation in patients suffering VF. The Heart Rhythm Society/European Heart Rhythm Association/Asia Pacific Heart Rhythm Society expert consensus defines IVF as a resuscitated cardiac arrest victim, preferably with documentation of VF, in whom known cardiac, respiratory, metabolic and toxicological causes have been excluded through clinical evaluation $[62,63]$. The possibility of IAs or cardiomyopathies should be excluded before making the diagnosis of IVF. Whether IVF is caused by variations in a single or multiple genes is unclear. Interactions between genetic variations and environmental factors such as electrolyte imbalance, sympathetic activities, and undetectable myocardial fibrosis may also play a role [63]. Genetic testing in collaboration with clinical evaluation can facilitate identification of the underlying pathophysiology of IVF. With recent advances in genetic testing and detection of a clinical subset of IVF, the incidence of IVF is expected to decline [63]. Although cardiomyopathies are not part of IA syndrome due to obvious structural abnormalities, a lethal ventricular arrhythmia can be the first manifesting symptom [64]. Evaluating whether these concealed cardiomyopathies are associated with an increased risk of lethal ventricular arrhythmia will evolve with molecular diagnostics. Table 3 shows the clinical characteristics of IVF in Korean and international registries [18,65-70].

Table 3. Clinical characteristics of patients with IVF in international registries

\begin{tabular}{|c|c|c|c|c|c|c|c|}
\hline Characteristic & $\begin{array}{l}\text { Korean IA } \\
\text { registry [18] } \\
(\mathrm{n}=99)\end{array}$ & $\begin{array}{c}\text { Herman et al. } \\
{\left[\begin{array}{c}65] \\
(\mathrm{n}=119)\end{array}\right.}\end{array}$ & $\begin{array}{c}\text { Remme et al. } \\
{[66]} \\
(n=37)\end{array}$ & $\begin{array}{c}\text { Champgne et } \\
\text { al. [67] } \\
(n=18)\end{array}$ & $\begin{array}{c}\text { Meissner et } \\
\text { al. [68] } \\
(\mathrm{n}=28)\end{array}$ & $\begin{array}{c}\text { Mewis et al. } \\
{[69]} \\
(n=18)\end{array}$ & $\begin{array}{c}\text { Crijns et al. } \\
{[70]} \\
(\mathrm{n}=10)\end{array}$ \\
\hline Mean age, yr & 41 & 48 & 35 & 42 & 42 & 48 & 37 \\
\hline Female sex & $18(22)$ & $46(39)$ & $11(30)$ & $5(28)$ & $13(46)$ & $9(50)$ & $2(20)$ \\
\hline ICD implantation & $88(89)$ & 111 (93) & $23(62)$ & $18(100)$ & $28(100)$ & $5 / 18(28)$ & $1(10)$ \\
\hline VF recurrence & NA & $10 / 89(11)$ & $16(43)$ & $7(39)$ & $2(11)$ & o & NA \\
\hline
\end{tabular}

Values are presented as number (\%).

IVF, idiopathic ventricular fibrillation; IA, inherited arrhythmia; ICD, implantable cardioverter defibrillator; VF, ventricular fibrillation; NA, not available. 


\section{ARRHYTHMOGENIC RIGHT VENTRICULAR CARDIOMYOPATHY}

Arrhythmogenic cardiomyopathy is a genetically determined abnormality of cardiac desmosomes predisposing to SCD, particularly in young patients and athletes. Although involvement is often biventricular, predominant involvement of the right ventricle is the original disease phenotype, hence ARVC. The histopathological hallmark of ARVC is the substitution of right ventricular myocardium with fatty or fibrous tissue $[71,72]$. Prior studies have revealed that the disease is caused by genetic variations in genes encoding cardiac desmosomes such as junction plakoglobin (JUP), desmoplakin (DSP), plakophilin $2\left(\mathrm{PKP}_{2}\right)$, desmoglein 2 (DSG2), and desmocollin 2 (DSC2) [73-77]. Patients with ARVC usually have structural abnormalities such as right ventricular dilation or wall thinning [78]. The diagnosis of ARVC may be difficult due to highly variable clinical presentations [79]. In the early phase, affected patients are at increased risk of lethal ventricular arrhythmias, but show no evidence of right ventricular abnormality and clinical symptoms; this is known as a concealed phase [79]. SCD can be the first clinical manifestation in patients affected by ARVC [8o]. Therefore, although ARVC is a cardiomyopathy with structural abnormalities, it can also be called an IA syndrome in which lethal ventricular arrhythmia occurs without obvious structural abnormality in the heart.

Cerrone et al. [81] demonstrated the coexistence of so- dium channelopathy and genetic PKP2 variations, suggesting $\mathrm{PKP} 2$ mutations may be a molecular substrate leading to the diagnosis of BrS. Accordingly, the overlapping phenotype may be explained by the emerging theory that ARVC and BrS are not completely different conditions, but the ends of a spectrum of structural myocardial abnormalities and sodium current deficiency that share a common origin as diseases of the connexome [82].

\section{GENETIC TESTING FOR INHERITED ARRHYTHMIAS}

In the past, the underlying causes of IA were not identifiable due to technical limitations. However, as advances in genetics have improved the understanding of IAs, genetic testing for the channelopathies and cardiomyopathies can have diagnostic, prognostic, and therapeutic implications, potentially influencing clinical decisions (Table 4) $[23,43,62,83-85]$. Recently, the next-generation sequencing technique has enabled multiple genetic variant analysis in a given patient, within a reasonable cost and time requirement. However, not all physicians can incorporate the results of genetic testing into a patient's care, because of potential pitfalls. Unlike solid cancers that are caused by somatic variants, the main outcome measurement in patients with IAs that are mostly caused by germline variants is an event of SCD

Table 4. Summary of genetic testing for inherited arrhythmias in clinical practice based on current guidelines and evidence $[23,43,62,83-85]$

\begin{tabular}{|c|c|c|}
\hline Disease & Major genes & Clinical utility \\
\hline Long QT syndrome & KCNQ1, KCNH2, SCN5A & $\begin{array}{l}\text { Confirm diagnosis; avoid genotype-specific triggers for } \\
\text { arrhythmias; may affect treatment and risk assessment; } \\
\text { can be useful in cascade family screening }\end{array}$ \\
\hline Brugada syndrome & $\mathrm{SCN}_{5} \mathrm{~A}$ & $\begin{array}{l}\text { Can support diagnosis; may be useful for risk } \\
\text { stratification; can be useful in cascade family screening }\end{array}$ \\
\hline $\begin{array}{l}\text { Catecholaminergic polymorphic } \\
\text { ventricular tachycardia }\end{array}$ & $\mathrm{RyR}_{2}, \mathrm{CASQ}_{2}$ & $\begin{array}{l}\text { Diagnostic criterion; can be useful in cascade family } \\
\text { screening }\end{array}$ \\
\hline $\begin{array}{l}\text { Arrhythmogenic right ventricular } \\
\text { cardiomyopathy }\end{array}$ & $\begin{array}{l}\mathrm{PKP}_{2}, \mathrm{DSP}, \mathrm{DSG} 2, \mathrm{DSC} 2 \\
\mathrm{TMEM}_{43}\end{array}$ & $\begin{array}{l}\text { Diagnostic criterion; may consider an arrhythmic risk; } \\
\text { can be useful in cascade family screening }\end{array}$ \\
\hline
\end{tabular}

KCNQ1, potassium voltage-gated channel subfamily Q member 1; KCNH2, potassium voltage-gated channel subfamily $\mathrm{H}$ member 2; SCN5A, sodium voltage-gated channel alpha subunit 5; RyR2, ryanodine receptor 2; CASQ2, calsequestrin 2; PKP2, plakophilin 2; DSP, desmoplakin; DSG2, desmoglein 2; DSC2, desmocollin 2; TMEM43, transmembrane protein 43. 
(i.e., 'all or nothing'), which is hard to predict. Standards and guidelines developed by the American College of Medical Genetics and Genomics can be used for the interpretation of sequence variants using five specific categories based on evidence: 'benign,' 'likely benign,' 'variants of unknown significance,' 'likely pathogenic,' and 'pathogenic' [86]. More expertise is required to interpret the results of various genetic evaluations. Proper genetic sampling, sample processing, adequate sequencing, and precise interpretation, correlated with the clinical situation, constitute the core competence in the field of cardiovascular genetics.

There are few data about whether an asymptomatic carrier of a pathogenic variant needs an ICD. Therefore, current guidelines still do not recommend the genotype-guided ICD as a primary prevention for SCD. However, sophisticated stratification for SCD risk using functional data, such as patch-clamp electrophysiology testing in induced pluripotent stem cells, will be implemented in cardiovascular genetics clinics as part of cascade screening for family members.

\section{CONCLUSIONS}

IAs are a group of primary electrical disorders that potentially predispose young individuals, with no evidence of structural heart disease, to SCD. Recent studies have suggested that a substantial proportion of SCD is due to IAs in East Asian people. BrS, LQTS, and IVF constitute the majority of IAs. Patients should be educated to avoid triggers, and an ICD is recommended for secondary prevention. Although each disease may have pathognomonic ECG findings, systemic evaluation is crucial for the diagnosis, and the role of genetic testing is expanding. Advances in genomic sequencing technology will facilitate identification of the underlying genetic pathophysiology of IA syndrome, and will propel physicians into the era of precision medicine in the field of cardiology.

\section{Conflict of interest}

No potential conflict of interest relevant to this article was reported.

\section{Acknowledgments}

This work was supported by a Korea University Grant (Jong-Il Choi) and a grant from Korea University Anam Hospital, Seoul, Republic of Korea (Jong-Il Choi), and in part by grants from the Basic Science Research Program through the National Research Foundation of Korea funded by the Ministry of Education (NRF2015R1DiA1Ao2061859 to Jong-Il Choi).

We thank all investigators of the Korean Inherited Arrhythmia Registry Network for their contribution to the pivotal basis for inherited arrhythmia research in Korea.

\section{REFERENCES}

1. Huikuri HV, Castellanos A, Myerburg RJ. Sudden death due to cardiac arrhythmias. N Engl J Med 2001;345:14731482.

2. Maron BJ. Sudden death in young athletes. N Engl J Med 2003;349:1064-1075.

3. Cerrone M, Priori SG. Genetics of sudden death: focus on inherited channelopathies. Eur Heart J 2011;32:2109-2118.

4. Sutherland GR. Sudden cardiac death: the pro-arrhythmic interaction of an acute loading with an underlying substrate. Eur Heart J 2017;38:2986-2994.

5. Robyns T, Kuiperi C, Breckpot J, et al. Repeat genetic testing with targeted capture sequencing in primary arrhythmia syndrome and cardiomyopathy. Eur J Hum Genet 2017;25:1313-1323.

6. John RM, Tedrow UB, Koplan BA, et al. Ventricular arrhythmias and sudden cardiac death. Lancet 2012;380:15201529.

7. Prystowsky EN, Padanilam BJ, Joshi S, Fogel RI. Ventricular arrhythmias in the absence of structural heart disease. J Am Coll Cardiol 2012;59:1733-1744.

8. Lee KH, Park HW, Eun JN, et al. Masked inherited primary arrhythmia syndromes in sudden cardiac death patients accompanied by coronary vasospasm. Korean J Intern Med 2017;32:836-846.

9. Fishman GI, Chugh SS, Dimarco JP, et al. Sudden cardiac death prediction and prevention: report from a National Heart, Lung, and Blood Institute and Heart Rhythm Society Workshop. Circulation 2010;122:2335-2348.

10. Goldberger JJ, Buxton AE, Cain M, et al. Risk stratification for arrhythmic sudden cardiac death: identifying the roadblocks. Circulation 2011;123:2423-2430. 
11. Junttila MJ, Castellanos A, Huikuri HV, Myerburg RJ. Risk markers of sudden cardiac death in standard 12-lead electrocardiograms. Ann Med 2012;44:717-732.

12. Kim Y, Ahn Y, Cho MC, Kim CJ, Kim YJ, Jeong MH. Current status of acute myocardial infarction in Korea. Korean J Intern Med 2019;34:1-10.

13. Albert CM, McGovern BA, Newell JB, Ruskin JN. Sex differences in cardiac arrest survivors. Circulation 1996;93:1170-1176.

14. Hayashi M, Shimizu W, Albert CM. The spectrum of epidemiology underlying sudden cardiac death. Circ Res 2015;116:1887-1906.

15. Murakoshi N, Aonuma K. Epidemiology of arrhythmias and sudden cardiac death in Asia. Circ J 2013;77:2419-2431.

16. Roh SY, Choi JI, Cho EY, et al. Abstract 19632: Inherited cardiac arrhythmias as a cause of sudden cardiac arrest in Korea: a cohort from National Health Insurance Service Database. Circulation 2017;136(Suppl 1):A19632.

17. Roh SY, Choi JI, Kim MS, et al. Trends in the use of implantable cardioverter-defibrillators for prevention of sudden cardiac arrest: a South Korean nationwide population-based study. Pacing Clin Electrophysiol 2019;42:1086-1094.

18. Oh SK. Genetic testing using next generation sequencing in inherited arrhythmia in the Korean population [thesis]. Seoul (KR): Korea University, 2019.

19. Priori SG. The fifteen years of discoveries that shaped molecular electrophysiology: time for appraisal. Circ Res 2010;107:451-456.

20. Goldenberg I, Moss AJ. Long QT syndrome. J Am Coll Cardiol 2008;51:2291-2300.

21. Patel C, Yan GX, Antzelevitch C. Short QT syndrome: from bench to bedside. Circ Arrhythm Electrophysiol 2010;3:401-408.

22. Roston TM, Yuchi Z, Kannankeril PJ, et al. The clinical and genetic spectrum of catecholaminergic polymorphic ventricular tachycardia: findings from an international multicentre registry. Europace 2018;20:541-547.

23. Priori SG, Blomstrom-Lundqvist C, Mazzanti A, et al. 2015 ESC guidelines for the management of patients with ventricular arrhythmias and the prevention of sudden cardiac death: The Task Force for the Management of Patients with Ventricular Arrhythmias and the Prevention of Sudden Cardiac Death of the European Society of Cardiology (ESC). Endorsed by: Association for European Paediatric and Congenital Cardiology (AEPC). Eur Heart J
2015;36:2793-2867.

24. Kapplinger JD, Tester DJ, Salisbury BA, et al. Spectrum and prevalence of mutations from the first 2,500 consecutive unrelated patients referred for the FAMILION long QT syndrome genetic test. Heart Rhythm 2009;6:12971303.

25. Tester DJ, Will ML, Haglund CM, Ackerman MJ. Compendium of cardiac channel mutations in 541 consecutive unrelated patients referred for long QT syndrome genetic testing. Heart Rhythm 2005;2:507-517.

26. Schwartz PJ, Crotti L, Insolia R. Long-QT syndrome: from genetics to management. Circ Arrhythm Electrophysiol 2012;5:868-877.

27. Schwartz PJ. Idiopathic long QT syndrome: progress and questions. Am Heart J 1985;109:399-411.

28. Priori SG, Napolitano C, Schwartz PJ, et al. Association of long QT syndrome loci and cardiac events among patients treated with beta-blockers. JAMA 2004;292:13411344.

29. Ahn J, Kim HJ, Choi JI, et al. Effectiveness of beta-blockers depending on the genotype of congenital long-QT syndrome: a meta-analysis. PLoS One 2017;12:e0185680.

30. Mazzanti A, Maragna R, Vacanti G, et al. Interplay between genetic substrate, QTc duration, and arrhythmia risk in patients with long QT syndrome. J Am Coll Cardiol 2018;71:1663-1671.

31. Lee YS, Kwon BS, Kim GB, et al. Long QT syndrome: a Korean single center study. J Korean Med Sci 2013;28:14541460.

32. Burns C, Ingles J, Davis AM, et al. Clinical and genetic features of Australian families with long QT syndrome: a registry-based study. J Arrhythm 2016;32:456-461.

33. Earle N, Crawford J, Smith W, et al. Community detection of long QT syndrome with a clinical registry: an alternative to ECG screening programs? Heart Rhythm 2013;10:233-238.

34. Goldenberg I, Horr S, Moss AJ, et al. Risk for life-threatening cardiac events in patients with genotype-confirmed long-QT syndrome and normal-range corrected QT intervals. J Am Coll Cardiol 2011;57:51-59.

35. Sauer AJ, Moss AJ, McNitt S, et al. Long QT syndrome in adults. J Am Coll Cardiol 2007;49:329-337.

36. Brugada P, Brugada J, Roy D. Brugada syndrome 19922012: 20 years of scientific excitement, and more. Eur Heart J 2013;34:3610-3615.

37. Ahn J, Choi JI, Shim J, Lee SH, Kim YH. Right ventricular 
compression mimicking Brugada-like electrocardiogram in a patient with recurrent pectus excavatum. Case Rep Cardiol 2017;2017:3047937.

38. Priori SG, Napolitano C, Gasparini M, et al. Natural history of Brugada syndrome: insights for risk stratification and management. Circulation 2002;105:1342-1347.

39. Ackerman MJ, Priori SG, Willems S, et al. HRS/EHRA expert consensus statement on the state of genetic testing for the channelopathies and cardiomyopathies: this document was developed as a partnership between the Heart Rhythm Society (HRS) and the European Heart Rhythm Association (EHRA). Europace 2011;13:1077-1109.

40. Bezzina CR, Lahrouchi N, Priori SG. Genetics of sudden cardiac death. Circ Res 2015;116:1919-1936.

41. Kusano KF, Taniyama M, Nakamura K, et al. Atrial fibrillation in patients with Brugada syndrome relationships of gene mutation, electrophysiology, and clinical backgrounds. J Am Coll Cardiol 2008;51:1169-1175.

42. Smits JP, Eckardt L, Probst V, et al. Genotype-phenotype relationship in Brugada syndrome: electrocardiographic features differentiate $\mathrm{SCN}_{5} \mathrm{~A}$-related patients from non-SCN5A-related patients. J Am Coll Cardiol 2002;40:350-356.

43. Yamagata K, Horie M, Aiba T, et al. Genotype-phenotype correlation of $S \mathrm{~N}_{5} A$ mutation for the clinical and electrocardiographic characteristics of probands with Brugada syndrome: a Japanese multicenter registry. Circulation 2017;135:2255-2270.

44. Sieira J, Conte G, Ciconte G, et al. Prognostic value of programmed electrical stimulation in Brugada syndrome: 20 years experience. Circ Arrhythm Electrophysiol 2015;8:777-784.

45. Delise P, Allocca G, Marras E, et al. Risk stratification in individuals with the Brugada type 1 ECG pattern without previous cardiac arrest: usefulness of a combined clinical and electrophysiologic approach. Eur Heart J 2011;32:169176.

46. Probst V, Veltmann C, Eckardt L, et al. Long-term prognosis of patients diagnosed with Brugada syndrome: results from the FINGER Brugada Syndrome Registry. Circulation 2010;121:635-643.

47. Eckardt L, Probst V, Smits JP, et al. Long-term prognosis of individuals with right precordial ST-segment-elevation Brugada syndrome. Circulation 2005;111:257-263.

48. Brugada P, Brugada R, Mont L, Rivero M, Geelen P, Brugada J. Natural history of Brugada syndrome: the prog- nostic value of programmed electrical stimulation of the heart. J Cardiovasc Electrophysiol 2003;14:455-457.

49. Brugada J, Brugada R, Antzelevitch C, Towbin J, Nademanee K, Brugada P. Long-term follow-up of individuals with the electrocardiographic pattern of right bundle-branch block and ST-segment elevation in precordial leads V1 to V3. Circulation 2002;105:73-78.

50. Miyazaki S, Shah AJ, Haissaguerre M. Early repolarization syndrome: a new electrical disorder associated with sudden cardiac death. Circ J 2010;74:2039-2044.

51. Wasserburger RH, Alt WJ. The normal RS-T segment elevation variant. Am J Cardiol 1961;8:184-192.

52. Klatsky AL, Oehm R, Cooper RA, Udaltsova N, Armstrong MA. The early repolarization normal variant electrocardiogram: correlates and consequences. Am J Med 2003;115:171-177.

53. Haissaguerre M, Derval N, Sacher F, et al. Sudden cardiac arrest associated with early repolarization. N Engl J Med 2008;358:2016-2023.

54. Rosso R, Kogan E, Belhassen B, et al. J-point elevation in survivors of primary ventricular fibrillation and matched control subjects: incidence and clinical significance. J Am Coll Cardiol 2008;52:1231-1238.

55. Tikkanen JT, Anttonen O, Junttila MJ, et al. Long-term outcome associated with early repolarization on electrocardiography. N Engl J Med 2009;361:2529-2537.

56. Antzelevitch C, Sicouri S, Litovsky SH, et al. Heterogeneity within the ventricular wall. Electrophysiology and pharmacology of epicardial, endocardial, and M cells. Circ Res 1991;69:1427-1449.

57. Yan GX, Antzelevitch C. Cellular basis for the electrocardiographic J wave. Circulation 1996;93:372-379.

58. Yoon N, Patocskai B, Antzelevitch C. Epicardial substrate as a target for radiofrequency ablation in an experimental model of early repolarization syndrome. Circ Arrhythm Electrophysiol 2018;11:e006511.

59. Nademanee K, Haissaguerre M, Hocini M, et al. Mapping and ablation of ventricular fibrillation associated with early repolarization syndrome. Circulation 2019;140:14771490.

6o. Haissaguerre M, Chatel S, Sacher F, et al. Ventricular fibrillation with prominent early repolarization associated with a rare variant of KCNJ8/KATP channel. J Cardiovasc Electrophysiol 2009;20:93-98.

61. Di Stolfo G, Palumbo P, Castellana S, et al. Sudden cardiac death in J wave syndrome with short QT associated to a 
novel mutation in $\mathrm{Na}_{\mathrm{v}} 1.8$ coding gene SCN10A: first case report for a possible pharmacogenomic role. J Electrocardiol 2018;51:809-813.

62. Priori SG, Wilde AA, Horie M, et al. HRS/EHRA/APHRS expert consensus statement on the diagnosis and management of patients with inherited primary arrhythmia syndromes: document endorsed by HRS, EHRA, and APHRS in May 2013 and by ACCF, AHA, PACES, and AEPC in June 2013. Heart Rhythm 2013;10:1932-1963.

63. Visser M, van der Heijden JF, Doevendans PA, Loh P, Wilde AA, Hassink RJ. Idiopathic ventricular fibrillation: the struggle for definition, diagnosis, and follow-up. Circ Arrhythm Electrophysiol 2016;9:e003817.

64. Ingles J, Bagnall RD, Yeates L, et al. Concealed arrhythmogenic right ventricular cardiomyopathy in sudden unexplained cardiac death events. Circ Genom Precis Med 2018;11:e002355.

65. Herman AR, Cheung C, Gerull B, et al. Outcome of apparently unexplained cardiac arrest: results from investigation and follow-up of the prospective cardiac arrest survivors with preserved ejection fraction registry. Circ Arrhythm Electrophysiol 2016;9:eo03619.

66. Remme CA, Wever EF, Wilde AA, Derksen R, Hauer RN. Diagnosis and long-term follow-up of the Brugada syndrome in patients with idiopathic ventricular fibrillation. Eur Heart J 2001;22:400-409.

67. Champagne J, Geelen P, Philippon F, Brugada P. Recurrent cardiac events in patients with idiopathic ventricular fibrillation, excluding patients with the Brugada syndrome. BMC Med 2005;3:1.

68. Meissner MD, Lehmann MH, Steinman RT, et al. Ventricular fibrillation in patients without significant structural heart disease: a multicenter experience with implantable cardioverter-defibrillator therapy. J Am Coll Cardiol 1993;21:1406-1412.

69. Mewis C, Kuhlkamp V, Spyridopoulos I, Bosch RF, Seipel L. Late outcome of survivors of idiopathic ventricular fibrillation. Am J Cardiol 1998;81:999-1003.

70. Crijns HJ, Wiesfeld AC, Posma JL, Lie KI. Favourable outcome in idiopathic ventricular fibrillation with treatment aimed at prevention of high sympathetic tone and suppression of inducible arrhythmias. Br Heart J 1995;74:408412.

71. Fontaine G, Fontaltaliran F. About the histology of arrhythmogenic right ventricular dysplasia. Circulation 1997;96:2089-2090.
72. Corrado D, Link MS, Calkins H. Arrhythmogenic right ventricular cardiomyopathy. N Engl J Med 2017;376:61-72.

73. McKoy G, Protonotarios N, Crosby A, et al. Identification of a deletion in plakoglobin in arrhythmogenic right ventricular cardiomyopathy with palmoplantar keratoderma and woolly hair (Naxos disease). Lancet 2000;355:2119-2124.

74. Huber O. Structure and function of desmosomal proteins and their role in development and disease. Cell Mol Life Sci 2003;60:1872-1890.

75. Gerull B, Heuser A, Wichter T, et al. Mutations in the desmosomal protein plakophilin-2 are common in arrhythmogenic right ventricular cardiomyopathy. Nat Genet 2004;36:1162-1164.

76. Pilichou K, Nava A, Basso C, et al. Mutations in desmoglein-2 gene are associated with arrhythmogenic right ventricular cardiomyopathy. Circulation 2006;113:11711179.

77. Syrris P, Ward D, Evans A, et al. Arrhythmogenic right ventricular dysplasia/cardiomyopathy associated with mutations in the desmosomal gene desmocollin-2. Am J Hum Genet 2006;79:978-984.

78. Marcus FI, Fontaine GH, Guiraudon G, et al. Right ventricular dysplasia: a report of 24 adult cases. Circulation 1982;65:384-398.

79. McGregor SM, Husain AN. A brief review and update of the clinicopathologic diagnosis of arrhythmogenic cardiomyopathy. Arch Pathol Lab Med 2015;139:1181-1186.

80. Thiene G, Nava A, Corrado D, Rossi L, Pennelli N. Right ventricular cardiomyopathy and sudden death in young people. N Engl J Med 1988;318:129-133.

81. Cerrone M, Lin X, Zhang M, et al. Missense mutations in plakophilin-2 cause sodium current deficit and associate with a Brugada syndrome phenotype. Circulation 2014;129:1092-1103.

82. Corrado D, Zorzi A, Cerrone M, et al. Relationship between arrhythmogenic right ventricular cardiomyopathy and Brugada syndrome: new insights from molecular biology and clinical implications. Circ Arrhythm Electrophysiol 2016;9:0003631.

83. Ackerman MJ, Priori SG, Willems S, et al. HRS/EHRA expert consensus statement on the state of genetic testing for the channelopathies and cardiomyopathies this document was developed as a partnership between the Heart Rhythm Society (HRS) and the European Heart Rhythm Association (EHRA). Heart Rhythm 2011;8:1308-1339.

84. Musunuru K, Hershberger RE, Day SM, et al. Genetic 
testing for inherited cardiovascular diseases: a scientific statement from the American Heart Association. Circ Genom Precis Med 2020;13:e000067.

85. Calkins H, Corrado D, Marcus F. Risk stratification in arrhythmogenic right ventricular cardiomyopathy. Circulation 2017;136:2068-2082.
86. Richards S, Aziz N, Bale S, et al. Standards and guidelines for the interpretation of sequence variants: a joint consensus recommendation of the American College of Medical Genetics and Genomics and the Association for Molecular Pathology. Genet Med 2015;17:405-424. 